\title{
The Importance of Trust in Knowledge Sharing and the Efficiency of Doing Business on the Example of Tourism
}

\author{
Elżbieta Kacperska $^{1}$ (D) and Katarzyna Lukasiewicz $^{2, *(D)}$ \\ 1 Institute of Economic and Finance, Warsaw University of Life Sciences, 02-787 Warsaw, Poland; \\ elzbieta_kacperska@sggw.pl \\ 2 Management Institute, Warsaw University of Life Sciences, 02-787 Warsaw, Poland \\ * Correspondence: katarzyna_lukasiewicz@sggw.pl; Tel.: +48-667-027-087
}

Received: 5 April 2020; Accepted: 8 June 2020; Published: 10 June 2020

\begin{abstract}
The ability to share knowledge in an organization may determine its success. Knowledge is one of the basic resources of an enterprise, being also the basis for undertaking various types of strategic actions. Knowledge management should be focused in the organization on such processing of all available information to lead to the creation of value defined by employees of the organization and by customers. In order to raise the issue of knowledge sharing, trust should be mentioned. Trust is a factor conditioning effective atmosphere and cooperation in an organization. The main purpose of the article is to present the relationship between trust and knowledge sharing, taking into account the importance of this issue in the efficiency of doing business. To formulate conclusions, data from surveys carried out in 148 different tourist facilities were used. Data were collected by applying the diagnostic survey method and by using a survey technique based on a prepared questionnaire. The results showed that trust is important in sharing knowledge and was found to play an important role in achieving a high level of performance efficiency. The study consists of an introduction, literature review, research results and discussion of results. At the end of the article, conclusions, restrictions and recommendations for future research are presented.
\end{abstract}

Keywords: trust; knowledge; efficiency; tourism; knowledge sharing

\section{Introduction}

Nowadays, in a knowledge-based economy, trust is becoming more and more important, treated as an extremely valuable element in company management. It influences interpersonal relations and causes that the employee has a greater willingness and awareness to control their own actions objectively. Knowledge that is a strategic resource can contribute to gaining a competitive advantage of an enterprise on the market. Transfer and exchange of knowledge is an essential basis for creating new ideas and developing new opportunities [1]. The most important aspect related to knowledge management is the need to share it and this applies to all employees of the enterprise. Knowledge is social in nature, in the sense that it arises from the process of continuous communication between people. Encouraging people to share knowledge rather than passively accumulate it is considered the first step towards effective, pro-development management in a modern enterprise. It is difficult to talk about knowledge if one does not take into account cooperation between people and the existence of conditions for cooperation [2]. According to Handy [3], trust is one of the life bases of every organization. He distinguished seven principles that are to govern trust in the enterprises of the future: trust cannot be blind, it must have boundaries, it requires learning, it is absolute, it requires bonds, requires personal contacts, requires leaders. Research on sharing knowledge somewhat narrows this issue either for analysis based on a specific industry or it focuses on certain aspects [4,5]. Knowledge sharing is a multi-level analysis model [6] and is considered important for the functioning of an 
organization [7]. It should be noted that scientists and practice are increasingly dealing with the issue of trust. This may be due to interest in soft management issues or the spread of cynical attitudes among employees. The trust used in the organization in the aspect of knowledge sharing can lead to good cooperation between colleagues, between subordinates and managers, which may further increase the efficiency of doing business. Among the tasks belonging to the process of sharing knowledge and disseminating it, we can distinguish three categories [8]:

- Knowledge duplication is a form of central control of the knowledge dissemination process. The purpose of this is to quickly provide knowledge to many employees. These resources should be distributed immediately and permanently so that users have access to them. Knowledge duplication concerns two important areas, which are the implementation of employees in organizational culture and their training. In the first case, it is about familiarizing employees with applicable norms and values, informing them about the role they will play in the organization and the requirements they will face, and in the second, about their professional development.

- Sharing experiences from previously implemented projects and documenting them. The tools supporting this process are IT networks (Internet, intranet, extranet), teamwork software or expert systems.

- Exchange of current experience, leading to the development of knowledge. The exchange of experience is possible thanks to the use of benchmarking teams (which look for the best solutions outside the company, their task is also to support the transfer of the best solutions created within the company, with particular emphasis on improvements in key processes in the organization), teams for the best solutions (informal exchange of information between employees with the possibility of using information and telecommunications technologies).

There is explicit and implicit knowledge in every organization. Trust plays a very important role in the process of obtaining tacit knowledge. This is intuitive knowledge, related to the experience of employees, and very often determines the functioning and success of an organization. The quiet-wise exchange is fostered by results-based trust and cognitive trust [9].

Trust always has a positive impact on the functioning of an organization. Knowledge transfer and exchange is a proven way to build trust in groups that enable shared learning. The process of building trust largely depends on the quality of knowledge and the pace at which knowledge is exchanged [10]. Trust depends on risk, is related to the dependence of two people, trust is accompanied by vulnerability, it is related to expectations about the future [11]. In addition, trust influences the organization's coordination, triggers creative thinking, encourages participation in transactions, promotes exchange of information, increases the company's ability to survive a crisis, is a key factor in building a network of cooperation and social cohesion and enables the creation of civic culture. It is an important element in teamwork, developing interpersonal relations, leadership, setting goals and negotiations $[10,11]$. Finally, trust is the main organizational value, achievement of which requires strong ethical attitudes, and in practical management of determining operational values. This value affects economic results and should be the subject of lasting desires and actions. It is a conviction that the undertaken actions will lead to achieving the set goals and obtaining benefits for all stakeholders [11].

The purpose of the article is to present the relationship between trust and knowledge sharing, taking into account the importance of this issue in the efficiency of doing business.

\section{Literature Review}

In the literature on the subject, it is believed that knowledge sharing is most positively related to knowledge management in organizations $[3,12,13]$. According to Paliszkiewicz [14], the objectives of knowledge management are as follows:

- increasing the results of business operations;

- $\quad$ achieving the company's goals;

- overall company development; 
- increasing employee motivation to improve company performance;

- maximum use of intellectual capital;

- development of learning organization, attitude of constant increase in the use of knowledge;

- supporting creativity, intuition and intelligence of employees;

- emphasis on continuous development and education of employees;

- making faster and wise decisions;

- creating an organizational culture supporting the development of knowledge.

From the definition perspective, knowledge sharing is the exchange of knowledge, experience and skills throughout the organization [15], it is a mutual transfer, i.e., the exchange of knowledge, understood as all information, abilities, skills and experiences relevant from the organization's point of view. The goal of this process is to transform the individual knowledge of each participant in the process into organizational knowledge [16]. Knowledge sharing is a centrally managed process of knowledge dissemination within a specific group of employees or knowledge transfer between individuals or teams of employees [16]. Knowledge transfer is the acquisition of knowledge from a database or the right source and its transfer to the recipient and its proper assimilation and use. G. von Krogh, I. Nonaka and M. Aben [17] indicate three conditions that are necessary for successful knowledge transfer:

- knowledge transfer participants must be aware of the circumstances in which they exchange knowledge,

- while waiting for the transfer of knowledge, its profitability must be studied,

- they must be properly motivated to carry out knowledge transfer.

E.K. Sveiby presents nine basic streams of knowledge flow in the organization [18]. In the internal communication these are the following transfers of knowledge:

- $\quad$ between units/employees;

- from employees to the internal structure;

- from the internal structure to the individual competences;

- within the internal structure (construction of integrated IT systems).

In the organization's communication with the environment, the streams of knowledge flow relate to the following transfer:

- from outside employees;

- from the environment to employees;

- from the environment to the internal structure;

- from the internal structure to the external structure (e.g., customer database);

- between organizations from the environment with which the company cooperates (e.g., how to make our clients contact each other).

Each time all activities related to the flow of knowledge are aimed at achieving greater efficiency. Trust is undoubtedly of great importance in the process of sharing knowledge. The specificity of the issue of trust concerns various scientific disciplines: management, psychology, sociology, economics and philosophy. Trust, in general, is a kind of assumption relating to the future behavior of other people, including certain assumptions that determine the further behavior of the individual [19].

Trust can also be defined as a subjective prediction of the level of probability of the attitude of the other party, determining the undertaking of specific actions by an individual or a group. This means that trust refers to a situation where the likelihood of the other party taking specific actions is so high that the individual or group decides to cooperate [20].

Organizational trust is a mechanism based on the assumption that other members of a given community are characterized by honest and cooperative behavior based on shared standards [21]. It can also be stated that trust is a certain belief based on which individual $\mathrm{A}$ in a particular situation 
agrees to dependence on individual B (person, entity, organization) with a sense of relative security, although negative consequences are possible [22]. Trust in the organization shown to other employees is based on the principle of reciprocity, according to which something should be done for a colleague, without expecting immediate compensation, but hoping that in the future this or that colleague will do a favor [23]. The trust that occurs in an organization is very often associated with the issue of organizational culture and the appropriate organizational climate [2,24]. It is important that the work atmosphere is favorable to cooperation and creative action. There are several factors expressing the phenomenon of trust [24]: instinctive feeling, person A will not act against person B, honesty and justice, positive expectation, positive interpersonal relationships, credibility, good will and finally effective action. According to Paliszkiewicz [25], trust in an organization has an impact on many factors, including motivation, training and development processes, which may further contribute to achieving higher operational efficiency.

Building trust in an organization is a long-term process and depends on many factors: organizational culture or broadly understood human resources policy applied to employees. In a situation where employees are convinced that the organization is properly fulfilling its goals and mission and treating employees correctly, then their credibility will continue to grow. They will represent an attitude open to change and innovation, which will contribute to the significant development of the company. Knowledge management is the awareness that sharing knowledge and its wise use is effective in the development of a company and employees cooperating with each other get better results. A knowledge-based economy is the most effective way of managing. The issue of knowledge sharing is not without significance here and is affected by [26,27]:

- factors depending on the organization (integration of the idea of haring knowledge with business strategy, organizational culture, teamwork support, direct management support and the example set by the leaders at the top, providing time and creating opportunities to transfer knowledge, atmosphere, work environment, lack of employee's fear of career development or loss of position, appreciating and rewarding behaviors related to knowledge sharing, communication system efficiency, availability and quality of information technology, company size, industry and organizational structure);

- interpersonal factors (interpersonal relationships, reciprocity, commitment, trust in the proper use of knowledge, identification with specific behavior, avoidance of embarrassment, sense of belonging to a group or team, seeking of community and cooperation);

- individual factors (greed, willingness to profit, fear of punishment, self-esteem, personality traits such as optimism, self-confidence, altruism, openness to experience, costs and time to acquire knowledge, age, gender, education, family status, work experience, work position);

- factors depending on knowledge (type of knowledge determining the possibilities and time of its transfer).

There is explicit and implicit knowledge in the organization. Trust plays a very important role in the process of obtaining tacit knowledge. This is intuitive knowledge, related to the experience of employees and very often determines the functioning and success of an organization. As Holste, Fields [9], Levin, Cross [28] wrote, the sharing of silent knowledge is fostered by results-based trust and cognitive trust, while competence and confidence trust favors the reception and its transfer.

Trust will always have a positive impact on the functioning of the organization. Thanks to this, it is possible to exchange knowledge in the organization and jointly build the culture of the learning organization, and this in turn can translate to the organization's successes.

In the following, the concept of efficiency and economic effectiveness will be presented.

There is strong competition in the modern market economy. Entity owners, including those from the tourism industry, must compete with each other. In addition to various aspects of competitiveness like, among others, location, tourist attractions, quality of services, etc., the economic efficiency of the project is also important. An entrepreneur in a market economy acts both as a buyer of necessary 
production factors and a seller of manufactured products or services. The manufacturing process and the technologies used to achieve economic benefits from the activities undertaken depend on the information held and his decisions. The concept of efficiency is ambiguous and interpreted differently. As E. Skrzypek points out, "it is defined by terms such as operational capability, positive result, profitability, productivity, effectiveness, purposefulness, rationality, cost effectiveness or utility" [29]. It refers to the relationship between various "effects, objectives, inputs and costs" [29] in different perspectives. This concept works in social sciences, is theoretically recognized by economists, sociologists, financiers, management specialists but also used in practice by economic analysts, company managers, etc. Juchniewicz indicates that the concept of efficiency refers to the economy as well as to business activities, that is to the functioning of enterprises, processes, management, decision making, management and finance or investment. The concept of efficiency comes from English and means effective, efficient, real [30]. In a broader sense, it means the benefits achieved by a given country, economy, enterprise from conducted activity [31]. In the literature, the concept of economic efficiency can be often found and it means "action without waste and focused on achieving the best result within the available resources and technologies [32]". Samuelson and Nordhaus point out that efficiency means there is no waste. They refer to the production capacity curve, indicating that an efficient economy is on the edge of production capacity [33]. This concept is also equated with allocation efficiency (also called Paret efficiency) meaning reaching the limit of possible utilities [33]. "Efficiency is a process in which society extracts maximum satisfaction from consumers using the available means" [34]. Economic efficiency can be considered in a narrow and broad sense. In a narrow sense, it is understood as the ratio between the value of expenditure incurred and the value of effects obtained thanks to it, that is, as the ratio between the amount of expenditure of used materials and the quantity of goods produced [35]. In a broad sense, it means the best results in the production or distribution of goods and services at the lowest costs [35]. It is through the prism of economic efficiency that the competitive possibilities of business ventures are determined. M. Szudy indicates that economic efficiency is one of the conditions for achieving economic success at the level of the entire economy as well as at the level of individual entities [36]. Economists consider efficiency in the context of the functioning of business entities in short and long periods, as well as on a microand macroeconomic scale. The microeconomic approach refers to the enterprise-it is a real ability to improve market position and achieved results [29]. According to Bojarski, macroeconomic efficiency consists in taking into account all direct and indirect effects of a given undertaking in the national socio-economic system and selecting this undertaking which is the most beneficial from the point of view of economic efficiency for the entire economy [37]. Szudy indicates that the effective functioning of the economy requires efficiency in three dimensions: static, dynamic and distribution. Static efficiency is identified with the management of specific resources in order to avoid waste, dynamic efficiency is associated with the process of increasing resources, assets through creativity and action despite the risk, and distribution efficiency relates to the recognition by society of a fair distribution of social product [38]. The efficient use of economic resources takes place in accordance with the principle of rational management. Efficiency in managing is one of the ways to assess the functioning of a household, enterprise, defined as the relation of effects to the means used [29]. The concept of efficiency is related to the functioning of the organization. It is often defined as the organization's ability to achieve its goals and strategies. One can distinguish organizational effectiveness and management effectiveness. Efficiency is therefore an important tool for measuring management effectiveness. The efficiency of an organization means its effectiveness and productiveness measured by the degree of achievement of relevant goals. According to Drucker, effectiveness is the degree of goal achievement [39]. Management effectiveness is a measure of the efficiency of the person in charge, his predispositions, it means also creativity in the formulation and achievement of goals set. Drucker points out that effectiveness is "a key element in human and organizational development that serves the self-realization and ability of modern society to survive" [39]. According to Lawlenss, the effectiveness of an organization, that is its 
efficiency, depends on the following variables: performance, morale (the degree to which members' needs are met), adaptability, flexibility, institutionalization and stability [40].

Various types of efficiency can be distinguished in the literature. J. Dabrowski distinguishes three types of economic efficiency: technical, economic and social. Technical management efficiency refers to "the properties of things used in the manufacturing process, indicating the relationship of benefits obtained (e.g., the number of operations performed) to expenditure, e.g., (energy consumption, time needed). In a broader sense (...) it applies to the entire production process (technics, technology, work organization) and indicates the relation of the amount of product produced to the factors of production involved" [41]. This efficiency is expressed in natural units and plays an important role in determining the other types of efficiency. The economic efficiency of management indicates that it can be analyzed in relation to the technical and economic and socio-economic aspects. This term is defined as the relation of obtained effects to incurred outlays taking into account prices of production factors [41]. Efficiency in a technical and economic context is expressed in cost intensiveness, outlay efficiency, productivity or profitability. It defines the relationship between the resources used and the utility values produced [42]. The analysis of economic efficiency in the social-economic context additionally takes into account the property rights to resources [41]. The third type of economic efficiency relates to social issues. In the efficiency analyzes, social effects of management are compared with the fulfillment of society's expectations. In a broader sense, it is associated with the management process, i.e., management rationality related to the well-being of the whole society. Pszczołowski after Kotarbiński also distinguishes three meanings of efficiency: objective (dealing with the development of science), economic and technical and social, understood as the relationship between inputs and the effects of these inputs manifested in the sphere of norms and values, society and ecology [43].

The literature on the subject analyzes the efficiency of business activities from various perspectives, it may relate to the efficiency of production or the efficiency of the organization. "A comprehensive approach to efficiency should include an assessment of: social purposefulness of operations, economic rationality of organizational processes and financial efficiency of management" [44].

It is also worth paying attention to the dimensions of efficiency. There are many dimensions of effectiveness in the literature-Martyniak, Bielski, Matwiejczuk, Pohl, Skrzypek, and Łoś wrote about it. The most common dimensions are as follows [45]:

- economic - in the context of economy, productivity, profitability,

- market—referring to the degree of satisfying the client's needs as well as in relation to the efficiency category in the strictly market and market economy dimension,

- system-indicating the state of the enterprise as a system,

- political-indicating the company's relations with the environment,

- cultural-refers to the cultural identity of society and the consolidation of values and norms by the organization,

- $\quad$ social-referring to the interests of employees and business owners in terms of social needs and roles,

- ecological-indicating the company's impact on the environment,

- financial-referring to financial indicators in the past,

- operational-referring to the productivity of manufacturing processes,

- behavioral-expressing the interests of organization participants, indicating their assessment,

- technological—related to the technological efficiency of the factors of production involved,

- developmental—referring to creating new products, acquiring new skills.

From the tourism perspective, the efficiency of a tourist enterprise's activities can be analyzed on an economic, social and ecological level, and broadly covers most of the dimensions mentioned.

In the next part of the study we will also discuss the issue of efficiency measures. 
Contemporary business entities conduct management efficiency analyzes on an ongoing basis, using various sets of measures. However, this measurement is often difficult, as Głodziński indicates, it may result from [46]:

- "Quantitative immeasurability of some (partial) effects/outlays,

- immeasurability of value of some (partial) effects/outlays imperfections of measuring tools,

- simultaneous use of the same outlays to obtain different, separately analyzed effects in the absence of an exact division possibility,

- the lack of a direct cause-effect relationship between effects and expenditures, while the presence of an indirect relationship (often only of an intuitive nature),

- lack of comparability between inputs and results as a result of their presentation using various measurement units".

One of the concepts of efficiency analysis is a multidimensional approach. Especially this type of approach, where "the assessment takes into account different aspects and different points of view" [47] is important in assessing service activities, including in the tourism industry. The multidimensional approach in the analysis of economic efficiency has been the subject of many studies [48,49].

Głodziński presents the procedure for transforming various categories of efficiency into economic efficiency, indicating that it requires the application of a specific standardization procedure. "For normalization to be possible, the impact of effects and production factors on the economic situation of the object (...) should be measurable. This means that the results and outlays identified must be quantified (quantitative measurability) and then valued (measurability of value)" [46].

The quantification of results and outlays takes place by determining the quantitative outlays for financial efficiency-financial aspects, for organizational effectiveness of organizational aspects, for technical efficiency of technical aspects, for social efficiency of social aspects for environmental performance of environmental aspects, and similarly for marketing and legal effectiveness of these aspects and evaluation of individual results and outlays in terms of value in monetary terms 1 [46].

Łoś A. proposed a model for measuring efficiency in a tourist enterprise, pointing to the mutual relations between three approaches to efficiency, in relation to the Kaplan and Norton concept [50]. He takes into account efficiency from a narrow perspective from an enterprise point of view and efficiency from a broad perspective from an economic and social point of view. It emphasizes important features that distinguish tourism, i.e., immateriality, incompatibility, as well as the special conditions of the business and services provided, which include seasonality as well as the rigidity of supply and the specificity of individual types of tourist services, e.g., catering, spa, hotel, etc. The proposed model covers three areas: dimension, main groups of criteria and detailed groups of criteria.

The proposed model includes three planes: dimension, main groups of criteria and detailed groups of criteria. The efficiency perspective has been divided into three zones I, II and III. The model includes, in zone I, dimension A divided into A1 and A2, in zone II, dimension A and dimension $\mathrm{B}$ divided into B1, B2, B3 and B4. Zone III contains next to A and B the dimension C divided into $\mathrm{C} 1$, $\mathrm{C} 2$ and $\mathrm{C} 3$. Zone I covers the economic and financial dimension-covering two efficiency criteria-A1 profitability of services and A2 service productivity and efficiency. The profitability of services in the case of hotels or tourist facilities can be measured by: ROA total assets return on investment, ROE equity return ratio, ROI return on investment, RevPar room revenue or GOPRAR gross operating profit per room. In the model of hotel efficiency evaluation as detailed measures of service productivity and efficiency (A2), the following were proposed: the indicator of the technical utilization of the facility, the indicator of the average number of nights spent and the indicator of the seasonal use of the accommodation facility. The main efficiency criteria for the organizational and market dimension, $B$, include:

B1-achievement of objectives, where the detailed measure of effectiveness for the hotel was the degree of achievement of the objective in relation to the expenditure on the purchase of the automatic reservation system (cost reduction by $10 \%$ ), 
B2-innovation, where the measure was proposed as detailed measure indicator of the number of introduced marketing innovations in relation to the expenditure on training in the Marketing and Advertising Department,

B3-market and economic value of the enterprise, assessed by means of the hotel's market share in relation to marketing costs and by the indicator of Customer Lifetime Value CLV, being a key element to its retention costs.

B4-the value for the customer, where the measure is the value of the benefits obtained by the customer in relation to the price paid by him. The socio-economic (C) dimension consists of the impact on the natural environment- $\mathrm{C} 1$, impact on the local community- $\mathrm{C} 2$ and impact on the local economy-C3. In the case of hotels, it is specified in the model that the measure of effectiveness is the Benefits/Cost $\mathrm{B} / \mathrm{C}$ ratio, where the measurement is carried out in units of monetary benefits and external costs in particular planes. Effective solutions occur when B > C2 [51].

\section{Materials and Methods}

In relation to the considerations made in this article, research was carried out on the issue of the importance of trust in knowledge sharing, including a reference to efficiency. The conducted research concerned the tourism industry. The survey covered 148 employees representing various types of tourism companies. The research was conducted at the turn of 2019/2020. The diagnostic survey method was used, using a questionnaire that included several parts:

- the first part included questions about trust;

- the second part covered the importance of trust in knowledge sharing;

- the third part was about the importance of trust in knowledge sharing regarding efficiency;

- the fourth part concerned information on the subject.

The survey was anonymous. Data collected during the research were presented graphically and in tabular form. The study involved 99 women (67\%) and 49 men (33\%). Most people are people up to 45 years of age with higher education. Most of the respondents were representatives of micro-enterprises (36\%), small enterprises (59\%) and medium-sized enterprises (5\%). All companies whose employees took part in the survey have been on the market for 2-5 years. The main purpose of the elaboration was to collect information in surveys from people who, working in a given organization for several years, could significantly convey their observations on the examined issue. Therefore, employees who worked in organizations operating on the market for a minimum of 2-5 years were taken into account. This period was considered sufficient to make observations and indicate relevant elements that were significant for the study. The research was carried out as a pilot study to identify the issue and to become well prepared for the actual research.

\section{Results}

During the research, the respondents were first presented with phrases regarding the perception of trust which allowed them to present their opinions on the meaning of this concept (Figure 1). The survey questionnaire used the approach developed in the literature [52].

As part of the study, the respondents received a spreadsheet in which areas of organizational trust were presented in six blocks:

- $\quad$ organization image: I am proud to be a part of this organization; I feel my position is stable;

- knowledge of the mission, vision and goals of the organization: I know the goals and development directions of the organization; I know the mission of my organization;

- management competencies and attitude: management communicates with employees; information and messages from superiors are precise; the organization uses the knowledge and experience of employees; I feel the support of my superiors; 
- employees' competences and attitude: I am a competent employee; I am an involved employee; people in the organization are happy to share their knowledge with colleagues; people in the organization openly admit mistakes if they made them;

- work atmosphere: there is a nice atmosphere at work; there is no lobbying in the organization; I always say what I think openly; employee evaluation is fair; assessment criteria are precise and clearly defined;

- remuneration policy as well as development and promotion opportunities: I am satisfied with the remuneration policy; the organization has a policy of equal opportunities; the organization is involved in employee training and development.



Figure 1. Organizational trust by respondents.

In each of the indicated research areas, they assigned a grade on a scale of 1-5 to each wording, where 1 meant weak significance and 5 important. In the areas of image of the organization, competencies and attitude of management, competences and attitude of employees or the work atmosphere, the most responses (about 90\%) indicated a grade 4 on a five-point scale. Slightly less optimistic scoring was received by the remuneration policy statement and the possibility of development and promotion-grade $3(77 \%)$. The weakest score (2) among the respondents was given to the area of knowledge of the organization's mission, vision and goals (96\%). The obtained results show that in the surveyed companies employees identify with the organization, they are proud that they work in it, and this is a very positive feeling, especially in the aspect of the process of sharing knowledge. It is also clear that the example "goes from above", i.e., the respondents emphasized the importance of drivers in the process of sharing knowledge. The respondents drew attention to the issues of pay policy in the companies in which they work. This proves that this is a very important element for employees, which if met could contribute to much higher achieved results. An area that raises many doubts is knowledge of the mission, vision and goals of the organization. The results obtained and the low rating confirm the fact that in many companies too little attention is paid to this issue.

For the needs of the study, selected analyzes were prepared with the use of the Statistica program. The scales were summed up and a box chart was prepared in which the data obtained during the research was used. The chart related to the areas of organizational trust in which the respondents used a 5-point Likert scale. The chart specifies the median, the first and third quartiles, and the maximum and minimum values. The box-and-whisker chart gives the opportunity to determine which assessments were usually indicated by the respondents (most often they indicated grade 4) and also, based on the width of the box, the answers diversity can be seen (the largest relates to pay policy as well as development and promotion opportunities) (Figure 2). 


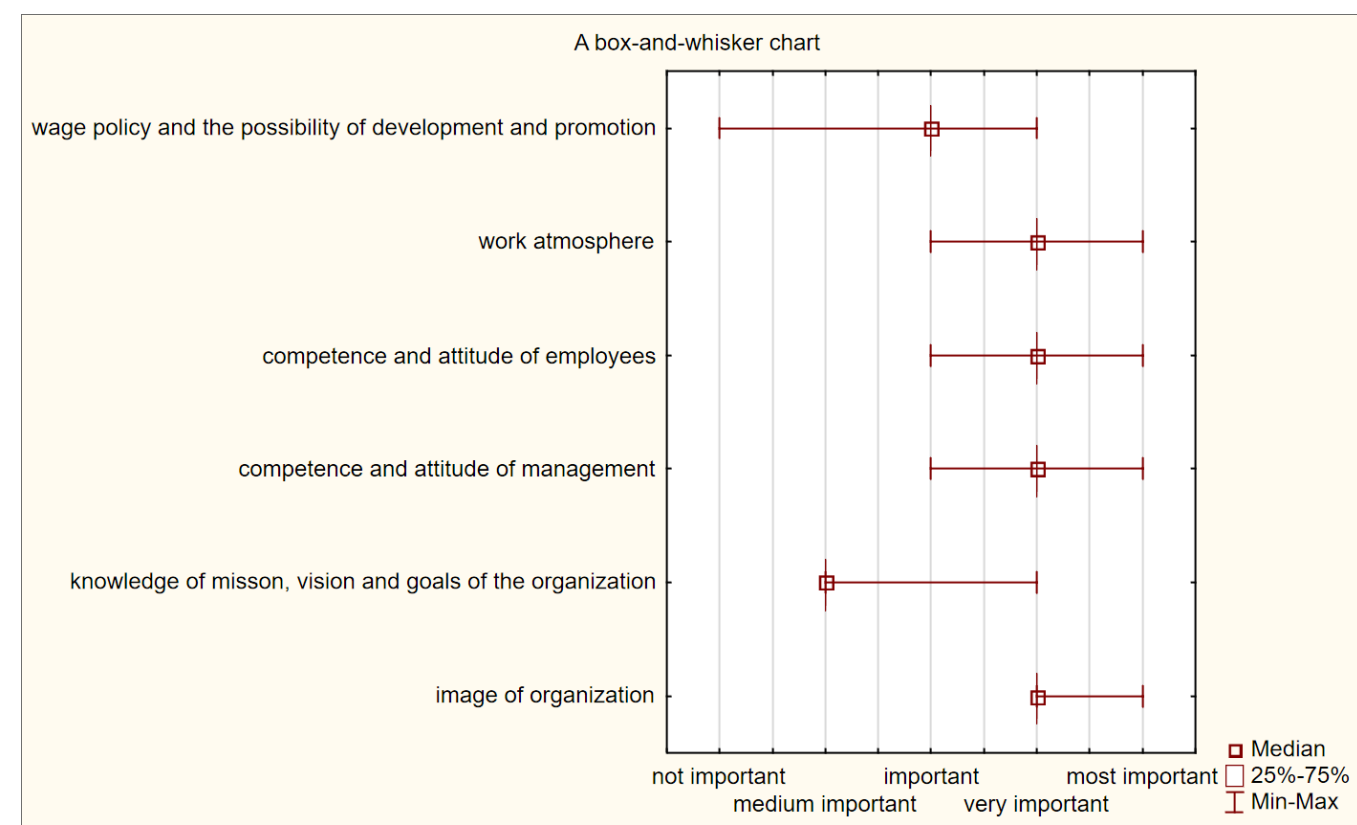

Figure 2. A box-and-whisker chart organizational trust by respondents.

Figure 3 shows how respondents assess the knowledge sharing process. Here, several statements are presented, which in the authors' opinion best reflect the importance of this issue. The obtained answers indicate the diversity of respondents' approach. Most people (95\%) said that this is a necessary process in every organization for it to develop and succeed on the market. Approximately (91\%) indicated that this is a process in which management's example plays a very important role. This means that respondents see a significant role of superiors in this process. For the respondents it was also important that in order to increase the willingness to share knowledge among employees, one should pay attention to additional remuneration that could improve employee satisfaction. A contented employee will work more efficiently what will also translate into better results achieved by the organization. The surveyed employees from the tourism industry also pointed out that in the area of knowledge sharing it is important to share it skillfully, what means that not every employee can do it.

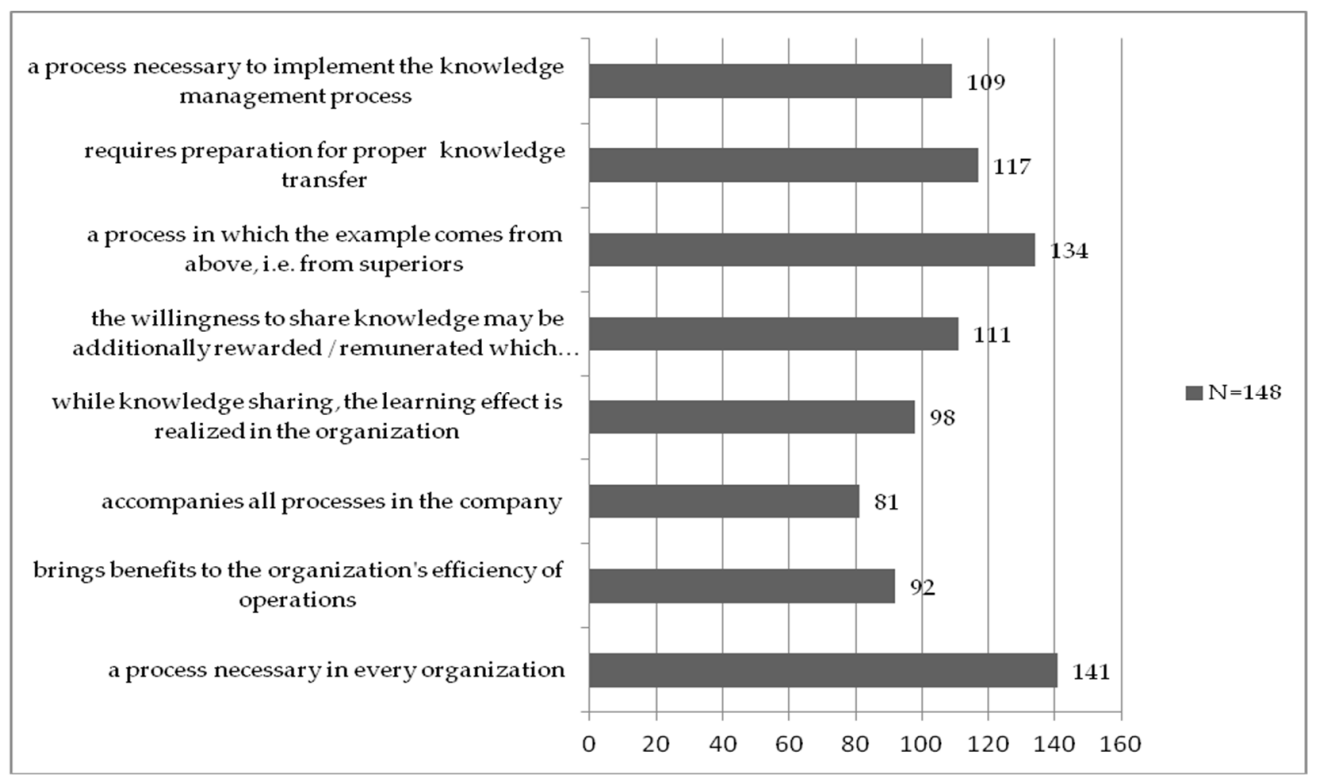

Figure 3. Knowledge sharing according to respondents. * respondents had the opportunity to indicate several statements. 
The research also used a combination of results on an ordinal scale-the so-called semantic differential, thanks to which it is possible to draw conclusions on which elements men and women pointed out in the analyzed area. The analysis of knowledge sharing shows that women largely paid attention to such factors as preparation (to convey knowledge well), the superior sets an example (an example comes from the top), additional gratification (for willingness to share knowledge). Men indicated: necessity of the process, efficiency of operation (Figure 4).

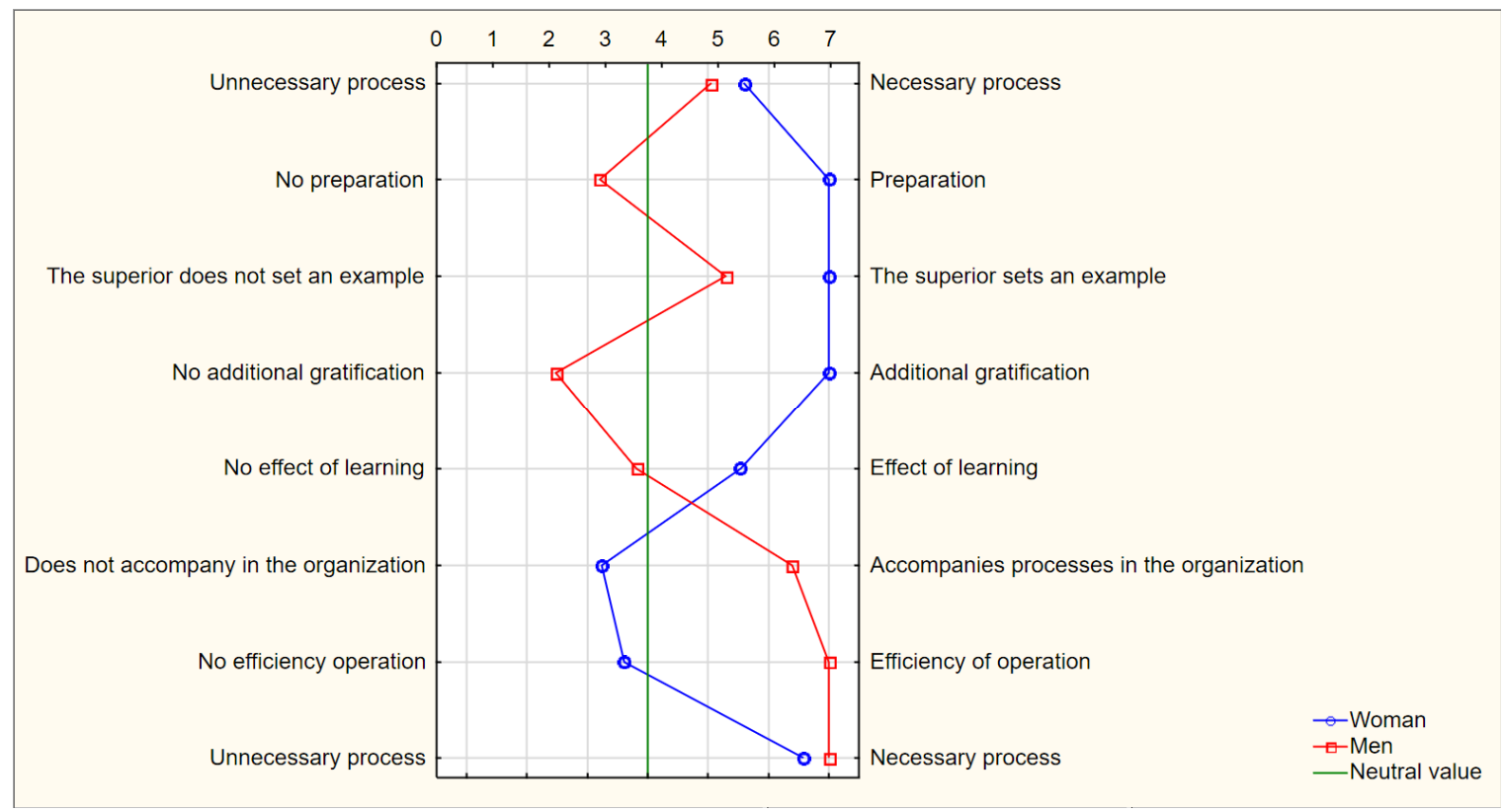

Figure 4. Knowledge sharing according to respondents (men and woman).

Table 1 lists the knowledge sharing barriers identified by the respondents. These barriers were divided according to the literature approach. Among organizational barriers, the lack of a transparent motivating system rewarding knowledge sharing (68\%) comes first, the less-important but also visible ones include 'outdated' organizational culture (7\%), no positive examples from the top of the organizational hierarchy $(8 \%)$ or lack of indicating appropriate benefits from knowledge sharing $(6.8 \%)$. As the less important respondents included: organizational hierarchy, lack of appropriate procedures or inadequate work atmosphere. Among individual barriers, the most important turned out to be the difference in the level of knowledge, experience $(45 \%)$, lack of time $(30 \%)$, or a sense of danger that sharing knowledge may harm us $(9 \%)$ or even a personal dislike of others $(7 \%)$. In the case of technological barriers, most respondents indicated a lack of training in the use of modern technologies in knowledge sharing (89\%), or a lack of consistency between expectations and technical capabilities $(7 \%)$. The question can be asked, how could one organizationally contribute to the removal of these barriers, is it even possible? Further in the research, the respondents were asked such a question. The obtained answers clearly indicate the great importance of financial incentives that would allow company employees to intensify the need for such activities. The surveyed employees of companies from the tourist industry also noted the importance of training in this area.

Another issue that was highlighted in the research concerned organizational support for this process. As many as 112 people said that the management pays great attention to this process. A tendency has been noticed that the smaller the company, the greater the emphasis on knowledge sharing and the indication on the high degree of trust among colleagues. The surveyed employees also noticed that a very important role was played by the work atmosphere, which made employees willing to participate in this process. In the next part of the research, the effects of knowledge sharing at the individual and organization level were highlighted. 
Table 1. Barriers to knowledge sharing according to respondents (\%).

\begin{tabular}{|c|c|}
\hline Organizational Barriers & $\mathrm{N}=148$ \\
\hline No transparent incentive system favoring knowledge sharing & 68 \\
\hline "Outdated" organizational culture & 7 \\
\hline No positive examples from management & 8 \\
\hline No indication of the sharing knowledge benefits & 7 \\
\hline Organizational hierarchy & 0,7 \\
\hline No consistency between knowledge sharing and achieving organizational goals & 5 \\
\hline No proper procedures & 3 \\
\hline Inadequate work atmosphere & 1 \\
\hline Individual Barriers & $\mathrm{N}=148$ \\
\hline Age differences & 3 \\
\hline Gender differences & 2 \\
\hline Cultural differences & 2 \\
\hline Differences in knowledge, experience & 45 \\
\hline The sense of danger that sharing knowledge can harm us & 9 \\
\hline No time & 30 \\
\hline Personal dislike of others & 7 \\
\hline No language knowledge & 1 \\
\hline Technological Barriers & $N=148$ \\
\hline No training in the use of modern technologies in knowledge sharing & 89 \\
\hline No IT support & 1 \\
\hline No consistency between expectations and technical capabilities & 7 \\
\hline Reluctance to use IT tools in the process of sharing knowledge & 3 \\
\hline
\end{tabular}

Table 2 presents the effects of knowledge sharing that are noticed by the respondents. These effects were divided into two areas: individual and organization. In the area of individual's effects, the respondents noted an increase in competences $(90 \%)$, personal development $(82 \%)$, loyalty to the company $(66 \%)$, openness to others $(68 \%)$ and a sense of importance $(82 \%)$. Other effects were: loyalty to the company, reduction of stress and proper organization of work. Another area of effects that was examined concerned the organization. At this level, respondents considered the improvement of operational efficiency (93\%), company development (93\%) and achievement of competitive advantage (93\%), as well as increased trust among colleagues $(93 \%)$ to be the most important. The next recommendations included improvement of work organization or appropriate atmosphere of cooperation. As part of the research, a question was also asked whether, in the opinion of the respondents, trust was an element that helped/facilitated the process of knowledge sharing. Here, the relationship between the age of respondents and the verification of this statement was noticed. People under the age of 35 have stated that trust played a key role in knowledge sharing. The respondents in the range $36-40$ no longer fully confirmed this statement. However, those over 40 years of age were very skeptical about trust. The respondents were also asked if they observed that over the last few years the efficiency of the company in which they work increased. 
Table 2. Effects of knowledge sharing at the individual and organization level (\%).

\begin{tabular}{|c|c|c|}
\hline Areas of Knowledge Sharing & Results & $\mathrm{N}=148$ \\
\hline \multirow{7}{*}{ Individual } & Increase of competence & 90 \\
\hline & Personal development & 82 \\
\hline & Loyalty to the company & 66 \\
\hline & A sense of importance & 82 \\
\hline & A proper work organization & 47 \\
\hline & Reducing stress & 66 \\
\hline & Openness to others & 68 \\
\hline \multirow{11}{*}{ Organization } & Improving operational efficiency & 93 \\
\hline & Company development & 93 \\
\hline & Achieving competitive advantage & 93 \\
\hline & Improving work organization & 70 \\
\hline & Knowledge transfer between different organizational units & 75 \\
\hline & Openness to news & 7 \\
\hline & Improving cooperation & 67 \\
\hline & The right working atmosphere & 80 \\
\hline & Increased trust among colleagues & 93 \\
\hline & Group integration & 53 \\
\hline & Equalizing of differences in knowledge & 13 \\
\hline
\end{tabular}

Source: own study * Respondents had the opportunity to choose a maximum of 3 effects in each area.

The next question in the research questionnaire concerned the issue of efficiency. People were asked about how they evaluate defined performance planes in the companies in which they work (the study did not take into account figures related to efficiency, but only the subjective assessment of the respondents). From the tourism perspective, the efficiency of a tourist enterprise can be analyzed on an economic, social and ecological level. For the purposes of the conducted research, a development plane was added to assess the effectiveness at various levels, taking into account the specificity of the tourism industry. Each of the subjects in each of the planes was to assign a grade on a scale of 1 (hardly visible) to 5 (very visible). The results are shown in Table 3.

Table 3. Subjective evaluation of effectiveness at different levels according to the respondents (\%).

\begin{tabular}{cccccccc}
\hline \multirow{2}{*}{ Specification } & \multirow{2}{*}{$\mathbf{N}$} & \multicolumn{5}{c}{ Assessment of the Importance } \\
\cline { 3 - 8 } & & $\mathbf{1}$ & $\mathbf{2}$ & $\mathbf{3}$ & $\mathbf{4}$ & $\mathbf{5}$ \\
\hline Efficiency on an economic level & 148 & 6.1 & 2.7 & 4.0 & 87.2 & 0 \\
\hline Efficiency on a social level & 148 & 0 & 5.4 & 79.1 & 12.8 & 2,7 \\
\hline Efficiency at the ecological level & 148 & 0.7 & 66.2 & 27.7 & 4.0 & 1.4 \\
\hline Efficiency at the development level & 148 & 0 & 0 & 5.4 & 94.6 & 0 \\
\hline
\end{tabular}

The economic efficiency rating was assessed by the vast majority $(87.2 \%)$ on grade 4 . Only $6.1 \%$ of respondents indicated that it is hardly visible. In the social plane, the highest number of respondents $(79.1 \%)$ gave a grade of 3 , no respondent gave the lowest score- 1 . In the ecological plane, the highest number of respondents indicated the lowest score $(66.2 \%)$, but the highest score also appeared (5) for $1.4 \%$ of respondents. Interesting results were obtained in the development plane. As many as $94.6 \%$ of respondents indicated note 4 . This shows that in the companies in which they work, a lot of attention is paid to new skills, which in the long run can contribute to increased business efficiency. 
The scales were summed up and a box chart was prepared in which the data obtained during the research was used. The chart related to the areas to determine the effectiveness assessment on various levels (economic, social, ecological and developmental). There, the greatest diversity of responses concerns social and ecological levels. The most frequently chosen answers relate to grades 3 and 4 . It is worth noting that very few people assigned the lowest grade 1 (Figure 5).

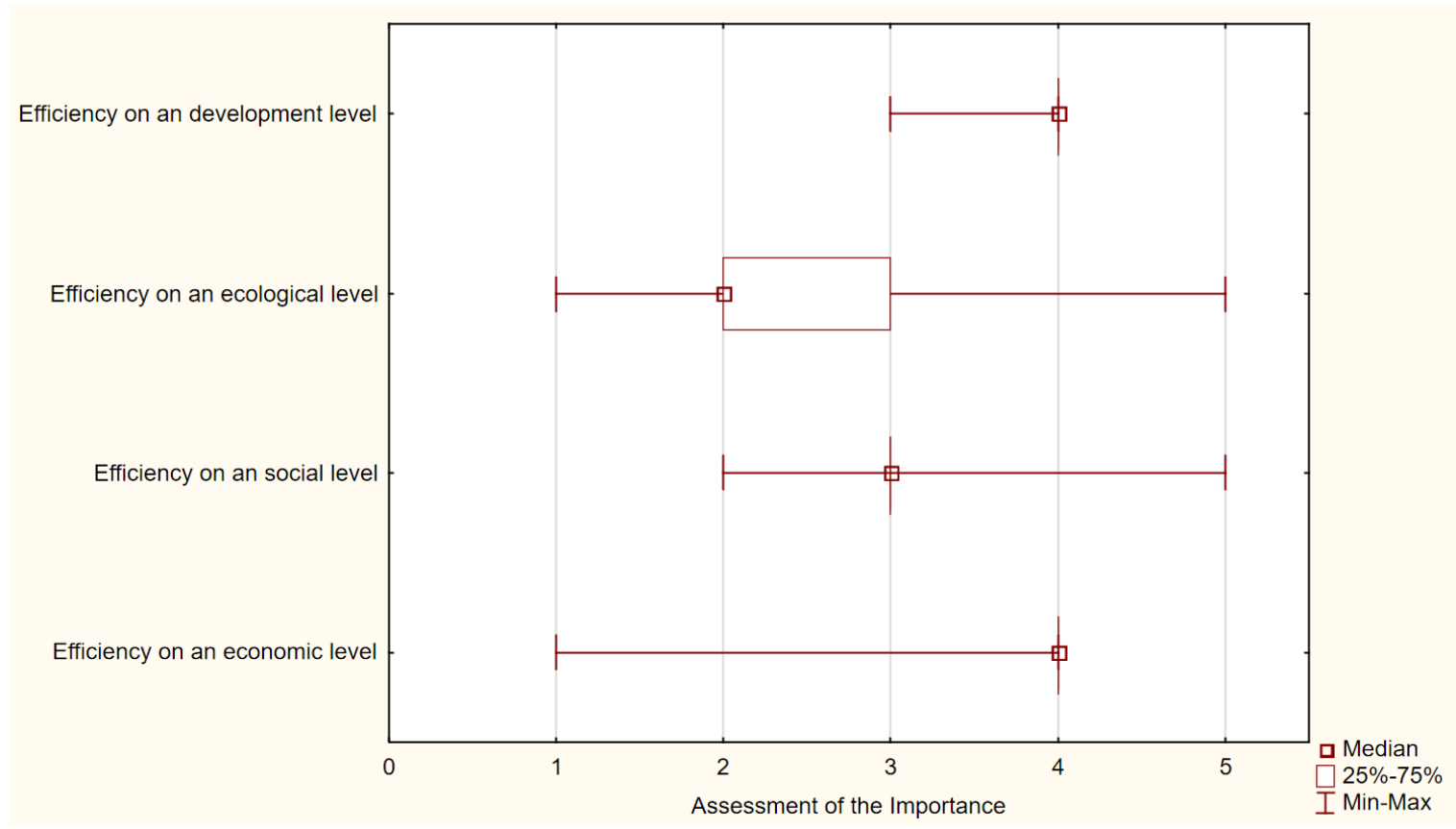

Figure 5. A box-and-whisker chart subjective evaluation of effectiveness at different levels according to the respondents.

\section{Discussion}

The research represents only a small sample of respondents who have expressed their subjective assessment of the importance of trust in knowledge sharing, taking into account the effectiveness of operations. The analyzed issue is undoubtedly important from the point of view of theoretical and practical considerations. The perception of the process of sharing knowledge also confirms a lot of scientific research. For example, Flaszewska [53] and Ryszko [54], based on the conducted research, stated that the most favorable factors for sharing knowledge could be financial incentives in the form of higher remuneration and additional bonuses, which are not always met in organizations. Paliszkiewicz [2] states that encouraging people to share knowledge is considered to be the first step towards effective, pro-development management in a modern enterprise. If difficulties arise in the area of knowledge sharing, they translate into a reduction in the efficiency, effectiveness and competitiveness of the organization. This statement is confirmed by research conducted in 500 largest American companies, which prove the scale of losses they suffered each year as a result of ineffective knowledge sharing or non-sharing of knowledge. The consequences of this state of affairs were, among others, project delays, professional burnout and waste of resources [55]. Sharing, flow and transfer of knowledge within an organization enables more cost and quality effective tasks to be carried out. It also enables the introduction of new participants to the knowledge exchange network, which is extremely important in the conditions of the information society, including the network [56]. The results have significant management implications. They indicate an important direction that should be strengthened in the use of all available human resource management tools so that, thanks to trust in the knowledge sharing process, the best economic results for the company can be achieved. This concept and its implementation requires an appropriate approach of the management because as the respondents noticed, "the example goes from above". The support of the supervisor and the quality 
of communication have a significant impact on the trust of the first-line employee [57]. The importance of trust is also indicated in their research by Jabłoński A., Jabłoński M. [58]. It is worth to use in the organization the incentive possibilities that exist to bring the expected result. The use of motivational tools will contribute to greater confidence, which will facilitate the process of sharing knowledge. Effective motivation will also lead to a favorable atmosphere among colleagues, i.e., it can be considered that in this way it will contribute to the construction of an appropriate organizational culture model, which will provide a positive background for implementing the knowledge sharing process.

\section{Conclusions}

Nowadays, trust is an important element in the functioning of any organization. It is crucial in building friendly interpersonal relations. Finally, it can be compared to a huge force that affects the efficiency of doing business. Trust causes an increased willingness to act and jointly pursue organizational goals. According to Rudzewicz [59], organizations should influence employee relations and their work satisfaction, what will result in an increased level of effectiveness of the entire organization. Based on the research carried out and the results obtained, it can be concluded that in the group of surveyed employees of organizations from the tourism industry, the knowledge sharing process is recognizable and is considered to occur in every organization. The conducted research is only a certain picture of the phenomenon, which for each organization is of great importance in achieving the desired efficiency of doing business. The greater the awareness of the benefits of sharing knowledge, the greater the guarantee of positive effects. Trust in this case plays a very important role because it determines the satisfactory achievement of results. The management, as can be seen from the conducted research, is also very aware of the importance of the process of sharing knowledge because as stated by the surveyed managers, they set a good example. It should be noted that this may determine the appropriate human resource policy and organizational culture focused on sharing knowledge. The respondents drew attention to many barriers that accompany this issue, thus expressing how much more needs to be done in this regard. There are also expectations in this respect regarding rewards for sharing knowledge or training in the use of various types of tools. The respondents also pointed out the visible effectiveness on various levels: economic, social or developmental. The study allowed for collecting opinions among employees of companies from the tourism industry. The tourism industry is specific when it comes to trust issues. Here, employees very often compete in some way, which may not contribute to a positive attitude towards knowledge sharing. It can be stated that the collected material is the basis for the research tool improvement and gives the prospect of a broader research in this field and industry, which can contribute to formulating a knowledge-sharing strategy in an efficiency-based organization what can lead to better and better results for companies from the tourism industry.

Author Contributions: Conceptualization, E.K. and K.Ł.; methodology, E.K. and K.Ł.; writing-review and editing, E.K. and K.Ł.; visualization, E.K. and K.Ł. All authors have read and agreed to the published version of the manuscript.

Funding: This research received no external funding.

Conflicts of Interest: The authors declare no conflict of interest.

\section{References}

1. Szabo, L.; Csepregi, A. Competences Found Important for Knowledge Sharing: Investigation of Middle Managers Working AT Medium and Large Sized Enterprised. IUP J. Knowl. Manag. 2011, 9, 42-43.

2. Paliszkiewicz, J.O. Knowledge Sharing and Trust in Small and Medium-Sized Enterprises; Scientific Papers of the Warsaw University of Life Sciences-SGGW-Economics and Organization of the Food Economy; Warsaw University of Life Sciences-SGGW: Warsaw, Poland, 2007.

3. Liebowitz, J. Key ingredient to the success of an organization's knowledge management strategy. Knowl. Process. Manag. 1999, 6, 37-40. [CrossRef]

4. de Carvahlo, A.F.; Lesca, H.; Canton, A.W.P. Intrinsic Motivation for Knowledge Sharing-Competitive Intelligence Process in a Telecom Company. J. Knowl. Manag. 2016, 20, 1282-1301. 
5. Saifi, S.A.; Dillon, S.; McQueen, R. The Relationship between Management Support and Knowledge Sharing: An Exploratory Study of Manufacturing Firms. Knowl. Process Manag. 2016, 23, 124-135. [CrossRef]

6. Kipkosgei, F.; Seung, W.K.; Suk, B.C. A Team Level Study of the Relationship between Knowledge Sharing and Trust in Kenya: Moderation Role of Collaborative Technology. Sustainability 2020, 12, 1615. [CrossRef]

7. Wang, C.-J. Linking Sustainable Human Resource Management in Hospitality: An Empirical Investigation of the Integrated Mediated Moderation Model. Sustainability 2019, 11, 1066. [CrossRef]

8. Probst, G.; Raub, S.; Romhardt, K. Knowledge Management in Organization; Oficyna Ekonomiczna: Kraków, Poland, 2002.

9. Holste, J.; Fields, D. The Relationship of Afeect and Cognition Based Trust With Sharing and Use of Tacit Knowledge. Acad. Manag. Proc. 2005, 1, 1-6. [CrossRef]

10. Skrzypek, E. Knowledge and trust management in the new economy. In Knowledge and Experience versus Contemporary Concepts and Tools of Organization Management; Toruński, J., Chrzaścik, M., Eds.; University of Natural Sciences and Humanities: Siedlce, Poland, 2015; pp. 7-28.

11. Bugdol, M. Dimensions and Problems of Managing a Trust-Based Organization; Publishing House UJ: Kraków, Poland, 2010; p. 18.

12. Chauvel, D.; Despres, C. A reviev of survey research in knowledge management: 1997-2001. J. Knowl. Manag. 2002, 6, 207-223. [CrossRef]

13. Gupta, K.S. A comparative analysis of knowledge sharing climate. Knowl. Process. Manag. 2008, 15, $186-195$. [CrossRef]

14. Paliszkiewicz, J.O. Leadership, Trust and Knowledge Management in Innovative Enterprises; CeDeWu Publishing House: Warsaw, Poland, 2019.

15. Lin, H.F. Knowledge sharing and firm innovation capability: An empirical study. Int. J. Manpow. 2007, 28, 315-316. [CrossRef]

16. Krok, E. Analysis of Employees Propensity to Share Knowledge on the Example of Research among University Employees; Studia Informatica 27, 129; Scientific Papers of the University of Szczecin; University of Szczecin: Szczecin, Poland, 2011.

17. Krogh, G.; Nonaka, I.; Aben, M. Making The Most of Your Company's Knowledge: A Strategic Framework. Long Range Plan. 2001, 4, 425.

18. Gierszewska, G. Building knowledge management strategies in enterprises. In Knowledge Management in Contemporary Organizations; Kisielnicki, J., Ed.; Monographs and Studies No. 4; Publishing House of the School of Commerce and Law. Ryszard Łazarski: Warsaw, Poland, 2003; p. 80.

19. Sztompka, P. Trust, Foundation of Society; Publishing House ZNAK: Kraków, Poland, 2007.

20. Gambetta, D. (Ed.) Can We Trust Trust? In Trust: Making and Breaking Cooperative Relations, Electronic ed.; Department of Sociology, University of Oxford: Oxford, UK, 2000; Volume 13, pp. 213-237. Available online: https:/www.csee.umbc.edu/ \{\}msmith27/readings/public/gambetta-2000a.pdf (accessed on 1 January 2020).

21. Fukuyama, F. Confidence. Social Capital and the Path to Prosperity; PWN Scientific Publisher: Warsaw/Wrocław, Poland, 2007.

22. Grudzewski, W.M.; Hejduk, I.K.; Sankowska, A.; Wańtuchowicz, M. Enterprise Trust Management. Concept, Tools, Applications; Oficyna Ekonomiczna, Wolters Kluwer Group: Cracow, Poland, 2009.

23. Bylok, F.; Pabian, A.; Kucęba, R. Building social trust as an element of preventing burnout. Hum. Work. 2011, 44, 53.

24. Stemplewska, M. The Importance of Trust and its Use in the Development of Intellectual Capital of an Enterprise; Research Reviews of Czestochowa University of Technology-Management 11; Czestochowa University of Technology-Management: Czestochowa, Poland, 2013; pp. 99-100.

25. Paliszkiewicz, J.O. Trust in Management; PWN Scientific Publishing House: Warsaw, Poland, 2013.

26. Krok, E. An Analysys of Employees Inclinations to Knowledge Sharing. Pol. J. Environ. Stud. 2009, 18, 187-192.

27. Krok, E. Personal Engagement in Knowlegde Sharing. Int. J. Manag. Cases 2009, 11, 11-22. [CrossRef]

28. Levin, D.Z.; Cross, R. The Strenght of Weak Ties You Can Trust: The Mediating Role of Trust in Effective Knowledge Transfer. Manag. Sci. 2004, 50, 1477-1490. [CrossRef]

29. Skrzypek, E. Economic efficiency as an important factor of the organization's success. In EffectivenessConceptualization and Conditioning; Dudycz, T., Osbert-Pociecha, G., Brycz, B., Eds.; Scientific Works of the Wrocław University of Economics: Wroclaw, Poland, 2012; Volume 262, pp. 313-314.

30. Cienkowski, W. A Practical Dictionary of Synonyms; Graf-Punkt Publishing House: Warsaw, Poland, 2000. 
31. Białecki, K.; Dorosz, A.; Januszkiewicz, W. Foreign Trade Dictionary; PWE: Warszawa, Poland, 1993.

32. Lockwood, B. Pareto Efficiency. In The New Palgrave Dictionary of Economics, 2nd ed.; Palgrave Macmillan: London, Great Britain, 2008.

33. Samuelson, P.A.; Nordhaus, W.D. Economics 1; PWN: Warsaw, Poland, 1998.

34. Samuelson, P.A.; Nordhaus, W.D. Economics; PWN: Warsaw, Poland, 2005.

35. Economic Dictionary for the Entrepreneur; Znicz Publishing House: Warsaw, Poland, 1996.

36. Szudy, M. Economic efficiency in dynamic terms and the efficiency of the economic system. In Economic Categories and Theories, and Economic Policy. Economic Studies; University of Economics in Katowice: Katowice, Poland, 2014; Volume 176, pp. 22-29.

37. Bojarski, W. System Effectiveness of Business Ventures; College of Management and Entrepreneurship B. Jański: Warsaw, Poland, 2001; pp. 10-15.

38. Szudy, M. Economic efficiency in dynamic terms and the efficiency of the economic system. In Economic Categories and Theories, and Economic Policy. Economic Studies; University of Economics: Katowice, Poland, 2014; pp. 2-6.

39. Drucker, P. Effective Manager; Modernity Library; Cracow University of Economics: Cracow, Poland, 1995.

40. Skrzypek, E. Effectiveness of operations in TQM-Quality costs. Qual. Issues 1999, 7, 11-12.

41. Dąbrowski, J. Methodical aspects of measuring the effectiveness of port enterprises. In Studies and Materials of the Institute of Maritime Transport and Trade; Klimek, H., Wach, D., Eds.; University of Gdańsk: Gdańsk, Poland, 2012; Volume 9, p. 34.

42. Nojszewska, E. Fundamentals of Economics; WSIP: Warsaw, Poland, 2010.

43. Pszczołowski, T. A Small Encyclopedia of Praxeology of Organizational Theory; Ossolineum: Wroclaw, Poland, 1978.

44. Skrzypek, E.; Skowronek, C.Z. Effectiveness of Material Management; PWE: Warsaw, Poland, 1997.

45. Matwiejczuk, R. Effectiveness-An attempt at interpretation. In Organization Review; Scientific Society of Organization and Management: Warsaw, Poland, 2000.

46. Głodziński, E. Economic Efficiency_Dilemmas of Defining and Measuring; Scientific Notebooks of the Silesian University of Technology; Organization and Management Series; Silesian University of Technology: Zabrze, Poland, 2014.

47. Bielski, M. Fundamentals of Management Theory and Organization; Beck Publishing House: Warsaw, Poland, 2002.

48. Czechiowski, L. Multidimensional Assessment of the Economic Efficiency of an Industrial Enterprise; University of Gdańsk Publishing House: Gdańsk, Poland, 1997.

49. Jurek, A.; Świtłyk, M. Application of multivariate comparative analysis to assess fertilization efficiency in the total economy of Poland in 1989-1997. In Agribusiness: Changes in Agribusiness and Rural Areas and Their Consequences; Scientific Works of the Wrocław University of Economics: Wrocław, Poland, 2002.

50. Kaplan, R.S.; Norton, D.P. The Balanced Scorecard: Measures that driv performance. Harvard Business Review. In Knowledge Management in Tourism and the Effectiveness of the Economy Tourist; Morawski, M., Ed.; Publishing House of the University of Physical Education: Wrocław, Poland, 1992; pp. 79-88.

51. Łoś, A. Dimensions of efficiency and its measurement in contemporary tourism. In Knowledge Management in Tourism and the Efficiency of the Tourism Economy; Morawski, M., Ed.; Publication of University School of Physical Education: Wrocław, Poland, 2012; pp. 79-88.

52. Rudzewicz, A. Trust in the Enterprise. Conditions-Relations-Measurement; UWM Publishing House: Olsztyn, Poland, 2016.

53. Flaszewska, S. Assessment of the process of sharing knowledge from the perspective of practitioners. Przeglad Organizacji 2019, 4, 45-50. [CrossRef]

54. Ryszko, A. Sharing knowledge in enterprises-Selected problems and conditions. Mod. Manag. Rev. 2015, 22, 149-159.

55. Babcock, P. Shedding Light on Knowledge Management. HB Mag. 2004, 49, 46-51.

56. Skrzypek, E. Barriers to sharing knowledge in an organization in the conditions of information society. Soc. Inequal. Econ. Growth 2018, 53, 45.

57. Seonggoo, J.; Insan, U.J. Antecendents and Consequences of Frontline Employee's Trust-in-Supervisor and Trust-in-Coworker. Sustainablilty 2020, 12, 716. [CrossRef] 
58. Adam, J.; Marek, J. Trust as a key Factor in Shoping the Social Business Model of Water Supply Companies. Sustainability 2019, 11, 5805. [CrossRef]

59. Rudzewicz, A. Trust in the enterprise-Significance and measurement. Manag. Financ. J. Manag. Financ. 2017, 15, 291-304. 